\title{
Energy audit experiences in foundries
}

\author{
M. Noro • R. M. Lazzarin
}

Received: 3 July 2014/ Accepted: 29 October 2014/Published online: 18 November 2014

(C) The Author(s) 2014. This article is published with open access at Springerlink.com

\begin{abstract}
Steel industry presents one of the highest energy demand of all the industrial sector. Foundries have a really relevant role both in economical terms and as regards the energy demand. The cost of energy represents several percentage points of the overall costs of a foundry. The electricity demand is very high, particularly for the induction melting furnaces. A large amount of thermal energy is obtained both from natural gas combustion and from the coal needed for the process of formation of cast iron in cupolas. Moreover, the plant services must be considered: one very energy consumer is compressed air production. Every factory is different from another so that the proposal of actions of energy savings or thermal recovers requires a detailed study of each plant considering the lay out and analysing the single processes with related energy needs and thermal levels. The co-operation of the University of Padua with the Centro Produttività Veneto allowed to plan a series of energy audits in some foundries located in Vicenza province. The experiences of the first facilities surveys and audits recommendations demonstrated both potential advantage of energy savings and the related difficulties, often due to the high investment costs. Anyhow the joint work of auditing between the university experts and the foundry technicians produced a better awareness on the critical points of the plant and a higher
\end{abstract}

Published in the Special Issue "8th AIGE Conference (Italian Association for Energy Management)".

M. Noro $(\bowtie) \cdot$ R. M. Lazzarin

Department of Management and Engineering, University

of Padua, Stradella S. Nicola, 3, 36100 Vicenza, Italy

e-mail: marco.noro@unipd.it

R. M. Lazzarin

e-mail: renato@gest.unipd.it rationality level in the evaluation of investments for the renewable of the machinery. Here, the method of performing the energy audits is described together with the very first results in terms of proposals for energy savings evaluated technically and economically.

Keywords Energy audit · Foundry · Thermal insulation · Cupolas $\cdot$ Induction furnace



\section{Subscript}

1

2

A, B, C, D, E States of the flue gas

F, G States of the steam

Loss Losses

Steam Steam

Steam turbine Steam turbine

\section{Introduction}

Energy management and related energy savings in industry sector are well known issues as various legislative acts and standards have been adopted in recent years in Italy (Directive 2006/32/EC on energy end-use efficiency and energy services adopted in Italy by D. Lgs. n. 115/08; Directive 
Fig. 1 Final uses of energy in Italy during the last 15 years [1]



2012/27/CE on energy efficiency, not yet adopted in Italy). Energy audit is the main tool that 2012/27/CE Directive foresees to obtain a suitable knowledge of the energy consumption profile of a factory; the final goal is to identify energy saving opportunities and to quantify them also from the economic point of view. A set of national and international standards have been recently released in order to:

- regulate how an energy management system has to be implemented (UNI EN ISO 50001, substituting the previous UNI CEI EN 16001);

- regulate how an energy audit has to be done (UNI CEI TR 11428; UNI CEI EN 16247-1);

- certificate the energy manager experts (UNI CEI 11339);

- certificate the energy service companies (UNI CEI 11352).

Notwithstanding during the last decade the use of energy in industry has been decreasing while civil uses has been increasing, it still remains one of the most important in Italy (23.6\% of the final uses in 2012) together with civil uses $(36.7 \%)$ and transports (30.2\%) (Fig. 1). In 2011, nearly one quarter of the total industry consumption has been consumed by metallurgic sector (23.9\%), followed by non-metallurgic mineral $(19.2 \%)$, chemical and petrochemical $(13.3 \%)$ and mechanics $(12.2 \%)$. During the period 1992-2011, two different phases may be identified: a quite slow increase till 2003 with a peak of 41 Mtoe ( $+17.9 \%$ with respect to 1992) followed by a fast drop (increased by the financial and economic crisis during the last years) [1]. In this second period, energy consumption of industry sector has decreased by more than a quarter with respect to 2003 , with the greatest decreases by non-
Table 1 Main data on cast iron foundry in Italy [2]

\begin{tabular}{|c|c|c|c|c|}
\hline & 2008 & 2011 & 2012 & $\begin{array}{l}2012 \\
\text { versus } \\
2011\end{array}$ \\
\hline Foundries (n.) & 163 & 154 & 152 & -2 \\
\hline Personnel (n.) & 12,250 & 11,140 & 10,895 & -245 \\
\hline Personnel per factory (n.) & 75 & 72 & 73 & +1 \\
\hline Turnover (G€) & 3.2 & 2.4 & 2.2 & $-8.0 \%$ \\
\hline Net production $(\mathrm{Mt})$ & 1.562 & 1.161 & 1.043 & $-10.2 \%$ \\
\hline $\begin{array}{l}\text { Average yearly net } \\
\text { production per factory }^{\left(\mathrm{t}_{\text {year }}-1\right)}\end{array}$ & 9,586 & 7,541 & 6,893 & $-9.0 \%$ \\
\hline
\end{tabular}

metallurgic minerals $(-31.5 \%)$ and chemical and petrochemical $(-30.2 \%)$. Metallurgic sector instead has substantially maintained quite constant its consumption (about eight Mtoe) [1].

In particular, foundry sector in Italy recorded an impressive decrease in net casting production from the beginning of the financial crisis: from $2.73 \mathrm{Mt}$ in 2007 to $1.96 \mathrm{Mt}$ in 2012, with $-33 \%$ for cast iron and $-22 \%$ for iron [2]. Concentrating on cast iron production, Italy is the ninth on a global scenario with 1.04 Mt in 2012 (China and India are, respectively, the first and the second cast iron producers in the world with 30.5 and $7.95 \mathrm{Mt}$ in 2011). Table 1 reports the main data about Italian cast iron foundry sector for the last years.

Disaggregated data concerning energy consumption and energy bill of foundries in Italy are not easy to find. One reference is the Energy Italian Foundry Association (Assofond Energia) that grouped together 81 foundries in 2013 supplying electrical energy and natural gas. In 2013, 
electrical energy supplied to Italian foundries was 553 GWh with a mean cost of $15 \mathrm{c} € \mathrm{kWh}^{-1}$ for plant connected to the medium voltage grid (typically $20 \mathrm{kV}$ ) (consider that meanly only $6.5 \mathrm{c} €$ is the energy quota while the great part of the cost of the $\mathrm{kWh}$ is due to different charges-transport, distribution and other charges like renewable energies incentives, nuclear plant decommissioning, etc.). Natural gas supplied by Assofond Energia was 13.2 $\mathrm{MSm}^{3}$ in 2013 with a mean cost of $35 \mathrm{c} € \mathrm{Sm}^{-3}$ (in this case the cost of energy is about $80 \%$ ) [3].

Some studies were previously made concerning energy in the foundry sector. Some authors presented trends in activity, primary energy and carbon dioxide emissions of the Mexican iron and steel industry, comparing it with five of the largest iron and steel world producers [4]. Some others made similar analysis for the Chinese [5], US [6] and Taiwanese [7] iron and steel industry. Thollander concentrated in Swedish iron foundry, studying the effect of rising electricity prices and quantifying an energy efficiency potential for a medium-sized Swedish iron foundry resulting from a thorough industrial energy audit [8]; other studies of the same Author [9, 10] provided an insight into barriers to energy efficiency in European foundries, considering several firm's characteristic (size, technologies adopted, country), and studied energy management practices and the driving forces for improved energy efficiency in the European foundry industry. The same Author again presented the use of methods for optimisation of dynamic industrial energy systems, studying how they can provide energy-intensive small and medium-sized enterprises like cast iron foundries with additional information when strategic investments are going to be made [11].

This paper reports on the energy performance of cast iron foundries together with some proposals for energy savings. It is based on the very first results of the cooperation between the University of Padua and the Centro Produttività Veneto in performing a series of energy audits in some foundries located in the Vicenza province (North Italy). Environmental and safety aspects, that are very important too, are not in the main scope of this work.

\section{Energy audit process}

Energy management in energy-intensive industries such as foundries is a very important and actual topic. New standards were developed to help the organizations to implement an effective energy management system, the most widely applied is ISO 50001:2011—Energy Management System. To correctly implement an energy management system, the first step is to conduct an energy audit that is a survey that examines the ways energy is currently used in the facility, also identifying some alternatives for reducing energy costs. Recently, new standards have been developed in this subject (the UNI CEI EN 16247-Energy audits set and, in Italy, the UNI CEI TR 11428-Diagnosi energetiche). The philosophy behind those standards is common: to pass from a "passive" vision (where the cost of energy is unavoidable and uncontrollable) to an "active" vision (where the cost of energy not only is under control, but moreover it is planned and can give an added value). Concerning the last point, in Italy an Energy Efficiency Certificates system is operating since 2004: every energy saving intervention in industries or organizations produces the certificates (each is worth 1 toe) that can be sold in a dedicated market (at a variable economic value, actually it is nearly 110 EUR) to the parties bound to energy efficiency interventions (typically electricity and natural gas distributors).

Following the suggestions of the cited standards, the energy audits in the foundries visited by the authors were implemented by the following actions:

- analysis of the energy consumptions and costs, by analysing the energy bills of the last 12-24 months for each energy vector of the foundry (electricity, natural gas, coke, etc.);

- survey on some general data of the industry, such as the geographical location/number of degree days/weather data of the facility and its location, the facility layout, the type and operating hours of the production and services plants, the equipment list (technical characteristics and models of both process-related and general energy-consuming equipment such as heater, boiler, chillers, air compressors, etc.);

- analysis of the energy consumed by the equipment. This is one of the crucial phases of the energy audit: each equipment has to be imputed by the energy consumed monthly and annually, differentiating between "process uses" (melting, moulding, etc.) and "plant services uses" (heating, compressed air, lighting, etc.). This stage can be performed by calculation (on the basis of power nominal data of the equipment, operating hours and work load factors) and/or by measuring data (using power/energy meters and/or a data logger systems to monitor the energy consumptions or energy-related parameters during a significant interval). Such activity needs some tools to be implemented such as walk-through tours, audit interviews, gathering detailed data (on the manufacturing process, the electrical supply system, the steam boiler and distribution system, the electrical motors, the heating, ventilation and air conditioning system, the lighting system, the air compressors and the compressed air distribution system, the building 
envelope and windows characteristics) and measurement instruments (wattmeter, thermometer, voltmeter, combustion analyzer, etc.);

- realizing an energy balance of the foundry, where energy fluxes are divided by inputs and outputs;

- calculating some key performance indicators that relate the different kinds of energy consumptions to some significant indicator. For the audited foundries, the gross and net cast iron production indicators were considered. The key performance indicators are the basis on which the foundry can, for example, attribute energy consumption to the different departments, monitor own performance during the months and the years, monitor own performance with respect to benchmarks;

- after calculating the key performance indicators, the audit should produce some energy saving recommendation ordered by the economic advantage of the investment. This is an important output of the energy audit, where the economic investment in each energy saving opportunity is evaluated by the net present worth and the payback time, giving a sort of list of priority interventions;

- the final step should be the continuous monitoring of the effects of the energy saving interventions realized on energy consumptions and performance indicators. This is important in order to understand which measures have been effective and which goals have been reached and which not.

The work is still in progress; the very first results of some of the stages above described are here reported.

\section{Cast iron production process and energy use}

Cast iron is an iron-carbon alloy, containing usually between 2.4 and $4 \%$ carbon. The minimum carbon content is $1.8 \%$. Silicon, manganese, sulphur and phosphorus are also present in various amounts. The production process can be divided into the following major activities:

- melting and metal treatment;

- preparation of moulds and cores;

- casting of the molten metal into the moulds, cooling for solidification and removing the casting from the moulds;

- finishing of the raw casting.

Each of these activities consumes energy (and materials obviously); "horizontal" activities (services) require energy as well: compressed air (as energy vector), water pumping, lighting, heating and cooling of buildings (offices and manufacturing departments), materials handling.
Figure 2 depicts the basic cast iron foundry process. Foundry scrap (selected scrap according to a certain chemical composition) or ingots are loaded (by a bridge crane with a magnet) in the existing liquid in the furnace to obtain the desired composition. The greatest part of energy consumption is due to the melting and metal treatment process, so to the furnaces. The main types in cast iron foundries are the cupola and the induction furnace: literature data report that for the former the percentage of furnace consumption on total foundry consumption is about $50 \%$, for the latter it can be up to $70 \%[12,13]$.

After loading the furnace, melting is obtained at about 1,450-1,500 ${ }^{\circ} \mathrm{C}$ (depending of the type of cast iron). During this phase, slag is removed from the hot metal with the help of a slag overflow notch; tapping can be automatic or manual from the melting pot into the ladles. Then cast iron is poured: the pour can be automatic or manual from the ladles to the moulds. On the moulding side, a basic distinction is made between permanent and lost moulds. Foundries casting in permanent moulds buy these metal moulds (dies) externally, but typically operate an in-house mould repair and maintenance shop. Foundries casting in lost moulds, often buy wooden, metal or plastic patterns (for their mould design) and operate an in-house pattern maintenance and repair shop. Moulds, cores and lost models are generally produced as part of the foundry process, starting from sand, alloying elements and other additives to give to this mixture the opportune moulding, cohesion and mechanical resistance. Successively, moulds and cores are assembled together than they are ready to the previous cited casting phase.

After the cooling phase of the castings, the shake-out and take-out stage allows to get the casting separated by the moulding box and the sand. In this phase, the circulating scrap and the sand are recovered to be re-used in the production process. Finally, the finishing phase includes the shot blasting (necessary to eliminate the remaining sand), the deburring (can be automatic or manual) and, eventually, the painting.

It is worth to stress that foundries utilise mechanisation and automation depending on the need for reproductivity and on the series sizes. The most flexible installation is typically the jobbing foundry. This produces a variety of products in small numbers (say $<100$ ). In general, this type of foundry applies manual moulding techniques with resinbonded sand moulds. The melting furnace works batch wise to allow an easy change of alloy.

For medium-sized series ( $<1,000$ parts), mechanised moulding and casting lines are used. Lost mould foundries utilise mould making machines. This implies the use of green sand, which allows fast mould making. The size of the mould making machine limits the maximum size of the castings. Casting can be performed manually or using a 
Fig. 2 The cast iron foundry process

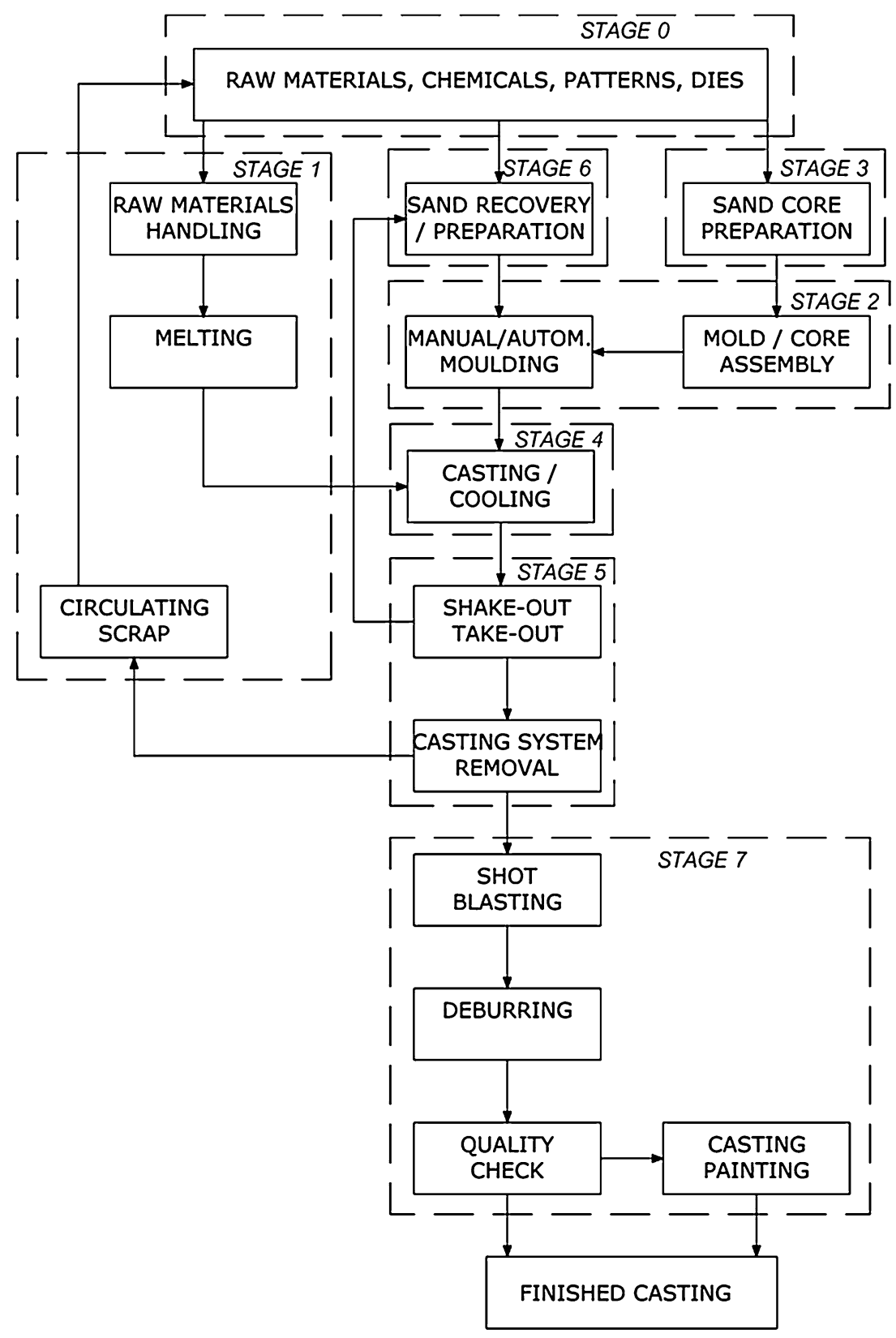

pouring machine. Auxiliary side processes, such as sand preparation, are operated in a semi-automated way with remote control. Both continuous furnaces (cupola, shaft) and batch furnaces are used.

Large series of small castings are made in flaskless green sand moulding. The main difference for mediumsized series is the further automation of the finishing, the quality control and the mould assembly. In reality, the experience of the Authors during the audits performed demonstrated that all these type of installation have been found, often present in the same foundry organized in two or three of these different ways of production.

As an example, Tables 2 and 3 report a sort of "energy balance" for one of the audited foundries (the one which
Table 4 is related, with five electric induction furnaces) with the allocation of the energy consumption for every single department. As can be seen, the most part of energy consumed in one year is electrical energy $(39,400$ vs. 5,860 MWh of thermal energy, that is natural gas); more than $80 \%$ of electricity is for the melting phase (furnaces), while almost all the natural gas is consumed by the burners for heating and drying the moulds and cores in the mould making department. The total annual energy consumption was attributed to the departments (month by month) by considering the power nominal data of the equipment, the operating hours and the work load factors as described in the previous section. Table 3 reports the energy bills and the PV plant $(220 \mathrm{~kW}$ peak 
Table 2 Yearly energy use per department and for type of utilisation for one of the audited foundries (year 2013)

\begin{tabular}{|c|c|c|c|c|c|c|c|c|c|c|}
\hline & \multicolumn{8}{|l|}{ Electrical } & \multicolumn{2}{|l|}{ Thermal } \\
\hline & \multicolumn{2}{|l|}{ Machinery } & \multicolumn{2}{|c|}{ Compressed air system } & \multicolumn{2}{|l|}{ Lighting } & \multicolumn{2}{|l|}{ Total } & \multirow[b]{2}{*}{$\mathrm{kWh}$} & \multirow[b]{2}{*}{$\%$} \\
\hline & $\mathrm{kWh}$ & $\%$ & $\mathrm{kWh}$ & $\%$ & $\mathrm{kWh}$ & $\%$ & $\mathrm{kWh}$ & $\%$ & & \\
\hline Sand mould & 99,105 & 0.3 & 8,850 & 1.0 & 40,416 & 12.6 & 148,372 & 0.4 & & \\
\hline Mould making & $3,363,515$ & 8.8 & 513,305 & 58.0 & 184,651 & 57.5 & $4,061,471$ & 10.3 & $5,187,644$ & 88.5 \\
\hline Sand core making & 101,128 & 0.3 & 44,250 & 5.0 & 39,334 & 12.2 & 184,712 & 0.5 & 124,822 & 2.1 \\
\hline Furnaces/laboratories & 647,219 & 1.7 & 88,501 & 10.0 & & & 735,720 & 1.9 & 63,765 & 1.1 \\
\hline Furnaces & $31,054,836$ & 81.3 & & & & & $31,054,836$ & 78.8 & & \\
\hline Robotized deburring & 76,857 & 0.2 & 35,400 & 4.0 & & & 112,257 & 0.3 & & \\
\hline M/G blast & 582,497 & 1.5 & 44,250 & 5.0 & & & 626,747 & 1.6 & 31,959 & 0.5 \\
\hline Manual deburring & 202,256 & 0.5 & 88,501 & 10.0 & & & 290,757 & 0.7 & 95,648 & 1.6 \\
\hline Automatized blast & 333,722 & 0.9 & 44,250 & 5.0 & & & 377,973 & 1.0 & & \\
\hline Painting & 182,030 & 0.5 & 8,850 & 1.0 & 11,063 & 3.4 & 201,943 & 0.5 & 208,036 & 3.5 \\
\hline Logistics/changing room/canteen & 101,128 & 0.3 & & & & & 101,128 & 0.3 & 135,996 & 2.3 \\
\hline Maintenance & 303,384 & 0.8 & 8,850 & 1.0 & 28,579 & 8.9 & 340,812 & 0.9 & & \\
\hline Offices building & 20,226 & 0.1 & & & 17,311 & 5.4 & 37,537 & 0.1 & 15,972 & 0.3 \\
\hline Aux (pumps, chillers, cooling tower) & $1,126,565$ & 2.9 & & & & & $1,126,565$ & 2.9 & & \\
\hline Total & $38,194,468$ & 100 & 885,008 & 100 & 321,353 & 100 & $39,400,829$ & 100 & $5,863,842$ & 100 \\
\hline
\end{tabular}

Table 3 Yearly energy consumption of electrical energy and natural gas, electrical energy production from the PV plant and cast iron production for the same foundry of Table 2 (year 2013)

\begin{tabular}{|c|c|c|c|}
\hline \multirow[t]{4}{*}{ Energy bills } & \multirow{2}{*}{ Electrical energy } & $39,199,096$ & $\mathrm{kWh}$ \\
\hline & & $5,844,022$ & $€$ \\
\hline & \multirow[t]{2}{*}{ Natural Gas } & 618,112 & $\mathrm{Sm}^{3}$ \\
\hline & & 228,787 & $€$ \\
\hline \multicolumn{2}{|c|}{ Electrical PV production } & 187,040 & $\mathrm{kWh}$ \\
\hline \multicolumn{2}{|c|}{ Cast iron production (gross) } & 34,853 & $\mathrm{t}$ \\
\hline \multicolumn{2}{|c|}{ Cast iron production (net) } & 24,542 & $\mathrm{t}$ \\
\hline
\end{tabular}

Table 4 Example of values for the variable of Fig. 3

\begin{tabular}{lcccc}
\hline$V_{\mathrm{A}}\left(\mathrm{m}^{3} \mathrm{~h}^{-1}\right)$ & $T_{\mathrm{A}}\left({ }^{\circ} \mathrm{C}\right)$ & $V_{\mathrm{B}}\left(\mathrm{m}^{3} \mathrm{~h}^{-1}\right)$ & $T_{\mathrm{B}}\left({ }^{\circ} \mathrm{C}\right)$ & $\begin{array}{l}\text { Efficiency } \\
\text { recuperator }\end{array}$ \\
\hline 55,000 & 950 & 110,000 & 950 & $50 \%$ \\
\hline$T_{\mathrm{E}}\left({ }^{\circ} \mathrm{C}\right)$ & $T_{\mathrm{C}}\left({ }^{\circ} \mathrm{C}\right)$ & $T_{\mathrm{G}}\left({ }^{\circ} \mathrm{C}\right)$ & $p_{\mathrm{G}}(\mathrm{MPa})$ & $\begin{array}{l}h_{\mathrm{G}} \\
\left.(\mathrm{kJ} \mathrm{kg})^{-1}\right)\end{array}$ \\
\hline 20 & 485 & 400 & 2.9 & 3,224 \\
\hline$T_{\mathrm{F}}\left({ }^{\circ} \mathrm{C}\right)$ & $p_{\mathrm{F}}(\mathrm{MPa})$ & $h_{\mathrm{F}}\left(\mathrm{kJ} \mathrm{kg}^{-1}\right)$ & Eff. HRSG & $\begin{array}{l}m_{\text {steam }} \\
\left(\mathrm{kg} \mathrm{s}^{-1}\right)\end{array}$ \\
\hline 50 & 0.012 & 2,387 & $80 \%$ & 1.24 \\
\hline Eff. cycle & $T_{\mathrm{D}}\left({ }^{\circ} \mathrm{C}\right)$ & & $\begin{array}{l}P_{\text {steam turbine }} \\
(\mathrm{kW})\end{array}$ \\
\hline $27.8 \%$ & 137 & 1,040 \\
\hline
\end{tabular}

power of poly-crystalline silicon) production, to close the energy balance.

In the next sections, the most important "energy consumers" in iron casting foundries are analyzed and possible energy saving interventions are proposed based also on the energy audits done by the Authors.

\section{Furnaces}

Cupolas

For small-medium foundries (handling less than 2,000 t per month of good casting), cold blast cupolas (which uses the blast at atmospheric pressure and at normal environmental temperature) are common. In order to reduce the $\mathrm{CO}$ emission and increase the energy efficiency, the conversion of cold blast furnaces to hot blast furnaces may be considered (this is economically justified only for bigger plants operating continuously). In hot blast cupolas, the combustion air (the "blast") is preheated typically by a recuperative heat exchanger. This involves the transfer of the residual heat of the flue gases (that can be at $900-1,000{ }^{\circ} \mathrm{C}$ ) to the combustion air by means of postcombustion of exhausts (collected at the top of the furnace, mixed with sufficient air and then burned in a unit) and the following heat exchange in a recuperator. Typically, the blast air is heated at temperatures of 500-600 ${ }^{\circ} \mathrm{C}$. Above these temperatures, problems arise with the sintering of furnace dust on the surface of the recuperator. The effect of 
Fig. 3 Draft of the recuperator + heat recovery steam generator solution for the hot blast cupola

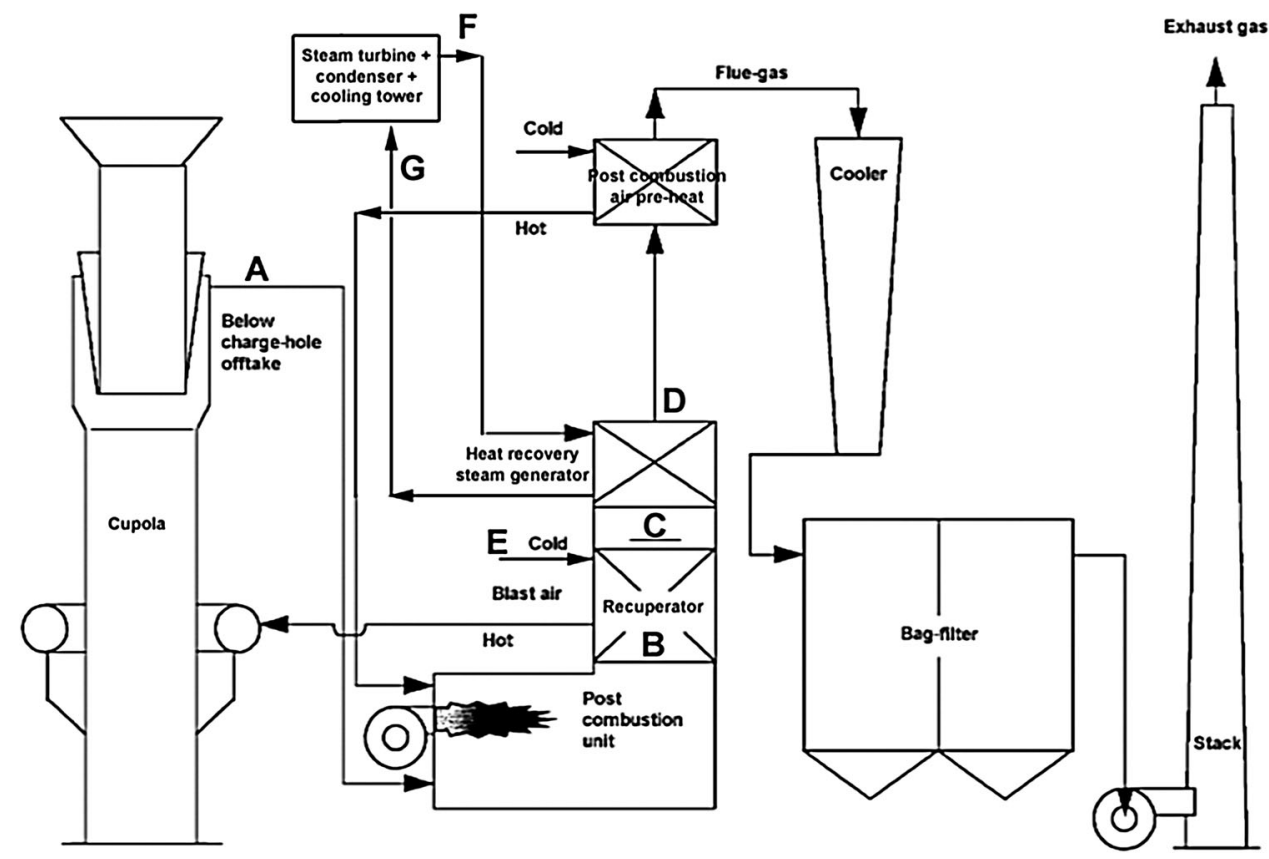

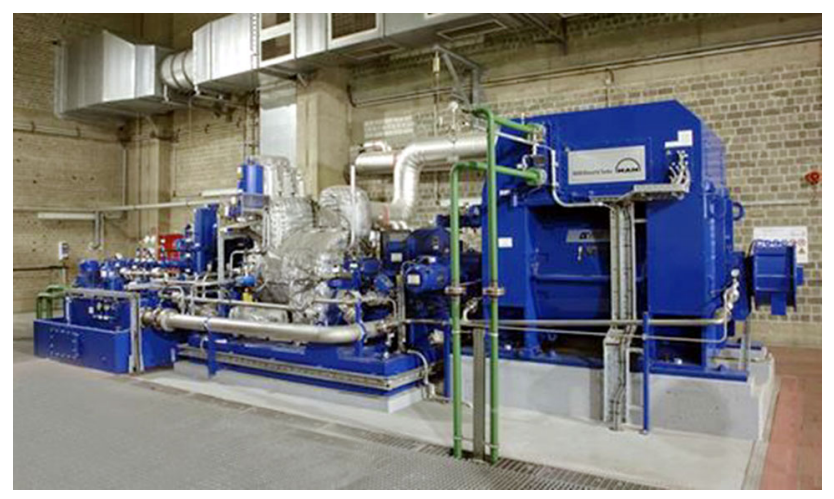

Fig. 4 Example of a small size steam turbine (courtesy of Man Diesel and Turbo)

air preheating on thermal efficiency can be in the order of $5 \%$ (the coke quality may affect the overall blast efficiency) $[14,15]$.

Given the high temperature of flue gases, it is suitable to think at using their enthalpy after the recuperator in order to produce electricity by a steam turbine (Fig. 3). This is done by means of a heat recovery steam generator (HRSG). For example, one of the foundries audited is a 5 days/week operated cold blast foundry with a melting capacity of $14 \mathrm{th}^{-1}$. To increase energy efficiency in melting, it would be possible to collect the off-gas (volumetric flow rate of $55,000 \mathrm{~m}^{3} \mathrm{~h}^{-1}$ at $950{ }^{\circ} \mathrm{C}$ ) below the charge-hole and then in a post-combustion unit. The waste gas would go then to hot blast production $\left(T=500{ }^{\circ} \mathrm{C}\right.$ ) by means of a recuperator (efficiency $50 \%$ ) and then to a steam boiler. The steam would be fed into a turbine to drive a generator. The residual heat could be used for preheating the combustion air of the post-combustion unit. Waste gas must then be cleaned in a bag filter at a required temperature around $160{ }^{\circ} \mathrm{C}$. Table 4 reports the main variables and their values, while Fig. 4 is a picture of a small steam turbine suitable for such a plant. The electrical power and the electrical efficiency that could be reached, considering an air excess of $100 \%$ in the post-combustion unit, is evaluated around, respectively, $1 \mathrm{MW}$ and $27 \%$ (Table 4).

A possible limit to the technological solution here proposed is the thermal inertia of the Rankine cycles that imposes a quite continuous availability of flue gas. A possible alternative to recover heat from the exhaust of cupolas when the gases are not continuously flowing are Organic Rankine Cycles (ORC). These use organic fluids (i.e. polysiloxane) that evaporate at lower pressures than water giving the possibility of lower maintenance costs and greater automation level of the plant. They are interesting when the heat source is at medium or low temperature (say below $400{ }^{\circ} \mathrm{C}$ ) because they have thermodynamic efficiency quite similar to Rankine cycles with no condensation during the expansion and lower thermo-mechanical stress of the turbine. For these reasons, they are earning some interest during the last years. Figure 5 depicts a standardize ORC plant: the working fluid is first pre-heated (7-3) and evaporated (3-4) by the heat source, then it is expanded in turbine (4-5) generating the electrical power. The fluid is than condensed (8-1) by the condenser cooled by water or air. The cycle is closed by pumping up the fluid pressure (1-2). In case of (relatively) high temperature heat 
Fig. 5 Schematic view and thermodynamic cycle of an ORC (courtesy of Turboden)

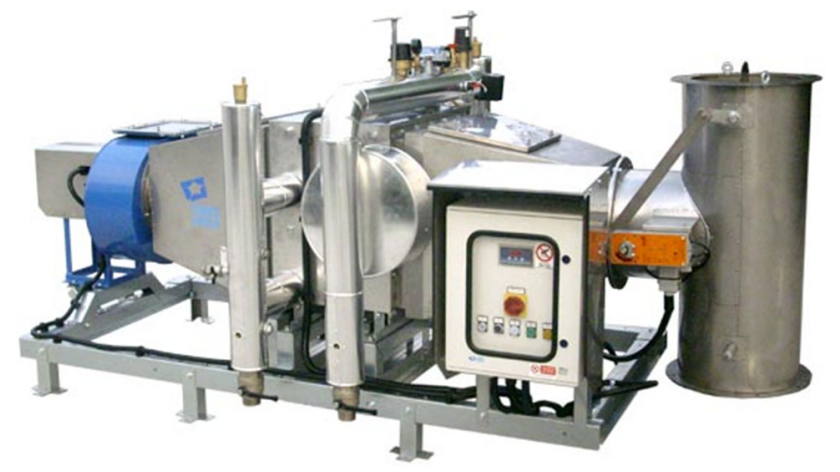

Fig. 6 Example of heat recovery system for hot flue gases installable directly on the chimney (courtesy of Comex Group)

sources, it is advantageous to add a regenerator to further pre-heat the fluid (2-7) using the enthalpy out of the turbine (5-8).

Obviously, a recuperator heat exchanger can be provided to produce hot water for process uses, heating or cooling. As an example, the product depicted in Fig. 6 is able to produce $256 \mathrm{~kW}$ of thermal power $\left(22 \mathrm{~m}^{3} \mathrm{~h}^{-1}\right.$ of hot water at $94{ }^{\circ} \mathrm{C}$ ) by means of $10,000 \mathrm{~m}^{3} \mathrm{~h}^{-1}$ of hot flue gases at $300{ }^{\circ} \mathrm{C}$, with an efficiency of $80 \%$. It can be easily installed directly on the chimney so on the roof of the factory.

Other ways to save energy in cupolas and other type of combustion furnaces used in foundries (like crucible and rotary furnaces) can be:

- regenerative burners: natural gas burners are commonly present in cupolas for the initial phases of the charges combustion; they are the main burner in crucible and rotary furnaces. One way to pre-heat the combustion air is by means of regenerative burners arranged in pairs. They work in cyclic fashion: while one burner fires, the exhaust gases flow through the other where their heat content is passed through a porous bed of ceramic

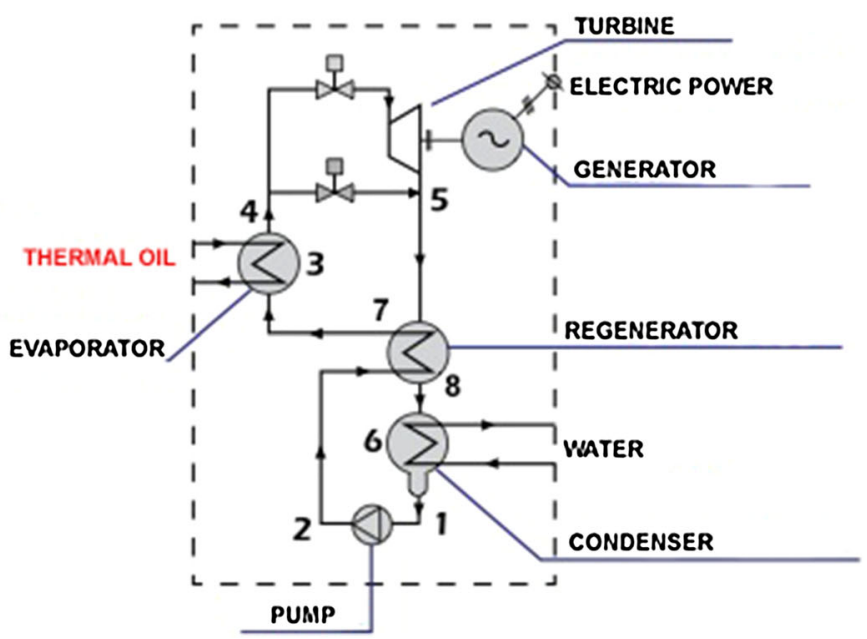

material around the burner and then stored. Next, the firing is reversed. Cold combustion air then passes through this material and becomes preheated, say to $600{ }^{\circ} \mathrm{C}$ (Fig. 7). In tested installations, a $17-20 \%$ increase in efficiency followed. The payback was less than one year [12];

- pre-heating of the scraps: the heat from the furnace offgases can be used for the purpose, or natural gas is used. This decreases energy input to the furnace, thus the melting is faster and the melting capacity increases.

\section{Electric induction furnaces}

The coreless induction furnace is a batch-melting furnace containing a water-cooled copper coil; the inside is internally refractory lined, the outside is insulated and enclosed in a steel shell, the top is often open for charging and deslagging operations. A first way to increase energy efficiency is to substitute mains frequency $(50 \mathrm{~Hz})$ furnaces with medium frequency (up to $250 \mathrm{~Hz}$ ) ones. The latters have a higher power density (up to $1,000 \mathrm{~kW} \mathrm{t}^{-1}$ ) than the formers $\left(300 \mathrm{~kW} \mathrm{t}^{-1}\right)$. This allows the use of a smaller crucible (up to a factor of three smaller) which results in a smaller total heat loss. The thermal efficiency of medium frequency furnaces is $10 \%$ higher than for the mains frequency types [14].

A typical coreless furnace can melt a ton of iron and raise the temperature of the liquid metal to $1,500{ }^{\circ} \mathrm{C}$ using less than $600 \mathrm{kWh}$ of electricity (Fig. 8). However, in practice, only a few foundries can achieve this level of specific consumption on a week-by-week basis. Prevailing circumstances in many foundries can restrict the scope for good energy management. As an example, one of the audited foundries by the Authors has five induction furnaces: Table 5 reports the main characteristics and energy performances as an example. 
Fig. 7 Example of regenerative burner (adapted from [21])

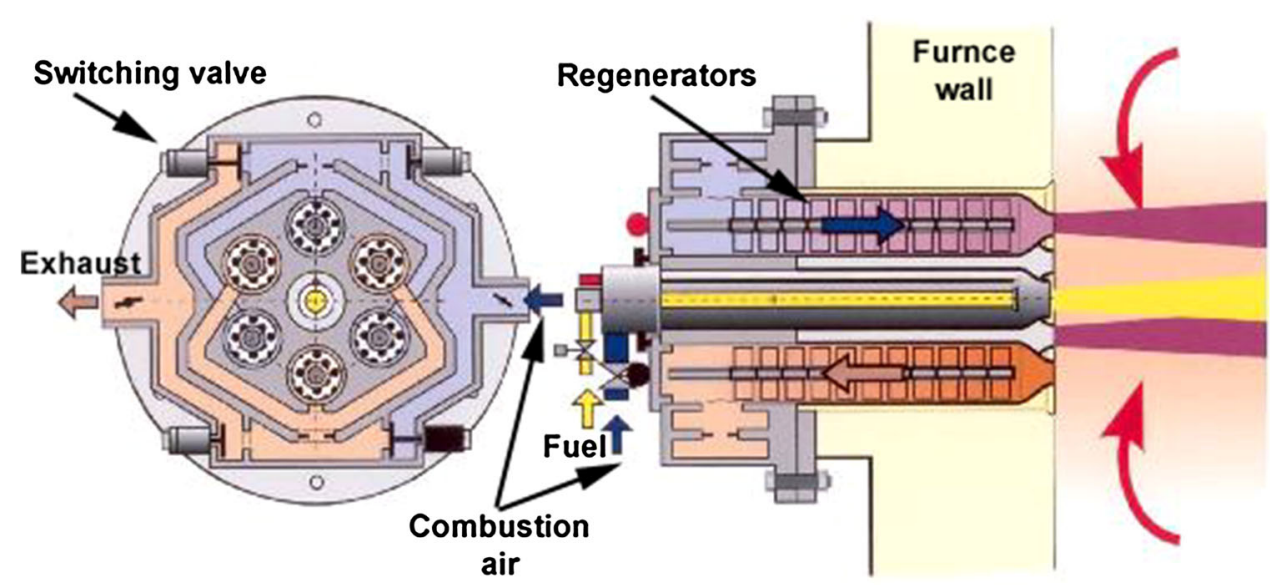

Fig. 8 Enthalpy to melt one tonne of cast iron (theoretical value at $\left.1500{ }^{\circ} \mathrm{C}: 396 \mathrm{kWh}\right)$

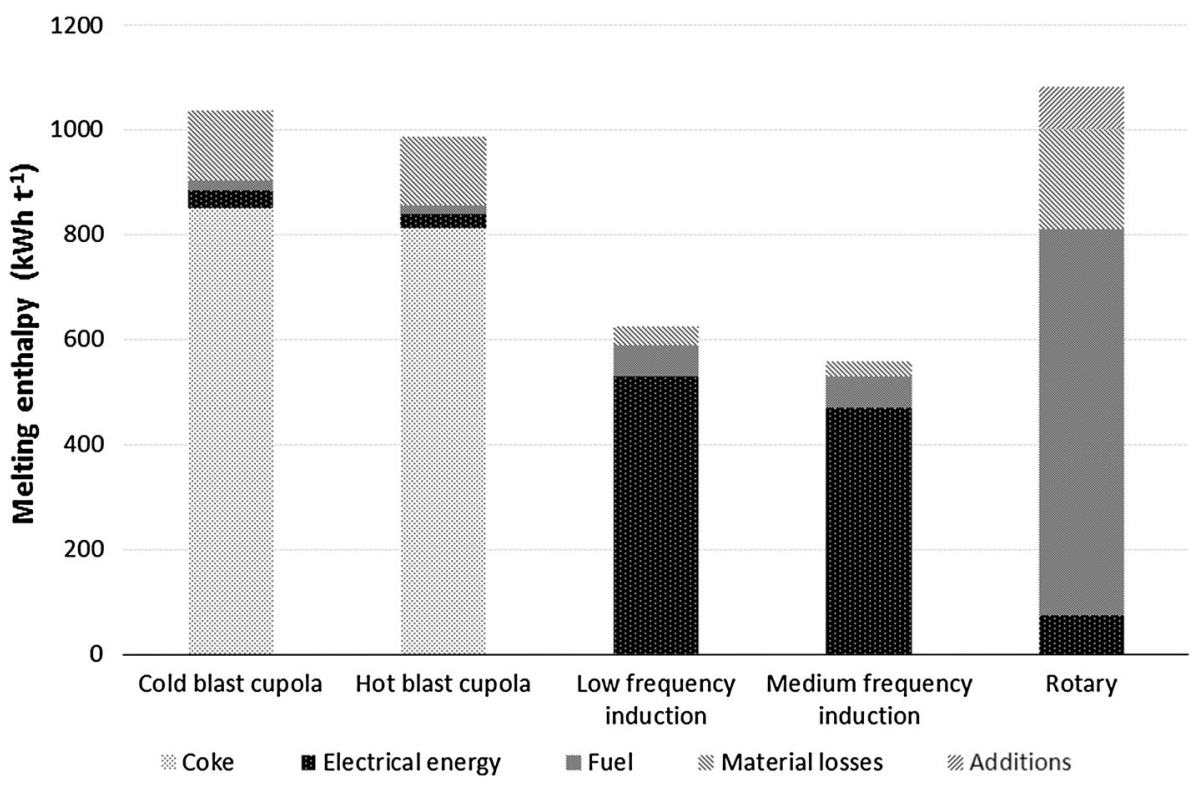

To decrease the specific electrical energy consumption for melting some process optimisation options could be:

- optimise feedstock condition: this involves avoiding rusty and dirty inputs, utilising optimum size and density input/scrap, and using cleaner carburisers. These measures shorten the melting time (10 min time longer means at least $600 \bullet(10 / 60)=100 \mathrm{kWh} \mathrm{t}^{-1}$ more), reduce the specific energy needed for melting and/or reduce the amount of slag formed. Shot-blasting the returning pieces (usually $10 \%$ in mass of returning pieces is sand) allows to save, for a $10 \mathrm{t}$ load furnace with $5 \mathrm{t}$ returning, till $25 \mathrm{kWh}$ per ton for the sand fusion;

- close furnace lid: opening times need to be minimised to prevent energy losses. The necessary opening times for charging, removing slag, temperature measuring, sampling and pouring vary typically between 50 and
$25 \%$ of the shift time. A well-fitted closed lid limits the surface heat loss to about $1 \%$ of the input power. It is quite easy to estimate that when a $1.5 \mathrm{~m}$ diameter lid of a $12 \mathrm{t}$ induction furnace is open for $5 \mathrm{~min}$ heat losses are of the order of $44 \mathrm{kWh}$;

- operate at maximum power input level (furnaces are more efficient in their use when they are being operated at maximum power input levels) and avoid excessive temperature and unnecessary superheating (good cooperation between the melting and moulding shop is essential in order to minimise the electricity usage); these are two aspects linked to the good production management capacity;

- finally, in the coils there is the greatest part of the furnace energy losses (about $70 \%$ ) and they have to be cooled typically to a temperature around $40-45{ }^{\circ} \mathrm{C}$ : this gives the possibility of useful heat recovery. In effect, 
the foundry audited actuated a thermal heat recovery by the five induction furnaces, producing $432,000 \mathrm{kWh}$ of thermal energy during 2013 used to heat offices (by means of low temperature ceiling fan-coils) and moulding department (by means of unit heaters). Figure 9 part a shows the cooled coils of one of the induction furnaces (not in use at that moment); part $b$ shows the plate heat exchangers connecting the furnaces cooling water circuit to the heating circuit (when heat is useful recovered) or to the cooling tower circuit (when heat is not requested); finally part c shows the moulding department heated by unit heaters (visible on the front and right walls). Table 6 reports measured data concerning the thermal power recovered and the furnaces electric consumption giving an estimation of the total melting power recovered for heating purpose (26\%, in line with references [12-14].

The use of PLCs and intelligent control systems can reduce significantly electrical energy consumptions and annual costs when a foundry has more than one induction furnace. Such systems record the demand and power
Table 5 Furnaces operation data during 2013 for one of the foundries audited

Fig. 9 Cooled induction coil of one of the furnace in an audited foundry (a). Plate heat exchangers of the cooling water heat recovery system (b). Moulding department heated by unit heaters (c)

\begin{tabular}{llll}
\hline Furnace & $\begin{array}{l}\text { Type (Production } \\
\text { capacity) }\end{array}$ & $\begin{array}{l}\text { Apparent } \\
\text { power }(\mathrm{kVA})\end{array}$ & $\begin{array}{l}\text { Electrical energy } \\
\text { consumption in } \\
2013(\mathrm{kWh})\end{array}$ \\
\hline Furnace 1 (CIME 2011) & Medium frequency $(28 \mathrm{t})$ & 2,700 & $4,489,333$ \\
Furnace 2 (Junker 1992) & Low frequency $(16 \mathrm{t})$ & 3,600 & $5,985,778$ \\
Furnace 3 (Junker 1992) & Low frequency (16 t) & 3,600 & $5,985,778$ \\
Furnace 4 (CIME 2005) & Medium frequency (16 t) & 4,000 & $6,867,740$ \\
Furnace 5 (CIME 2007) & Medium frequency (55 t) & 4,500 & $7,726,208$ \\
Total cast iron & & Furnace specific \\
production (gross) (t) & & electricity consumption \\
33,550 & & (kWh t & \\
& & 926 &
\end{tabular}
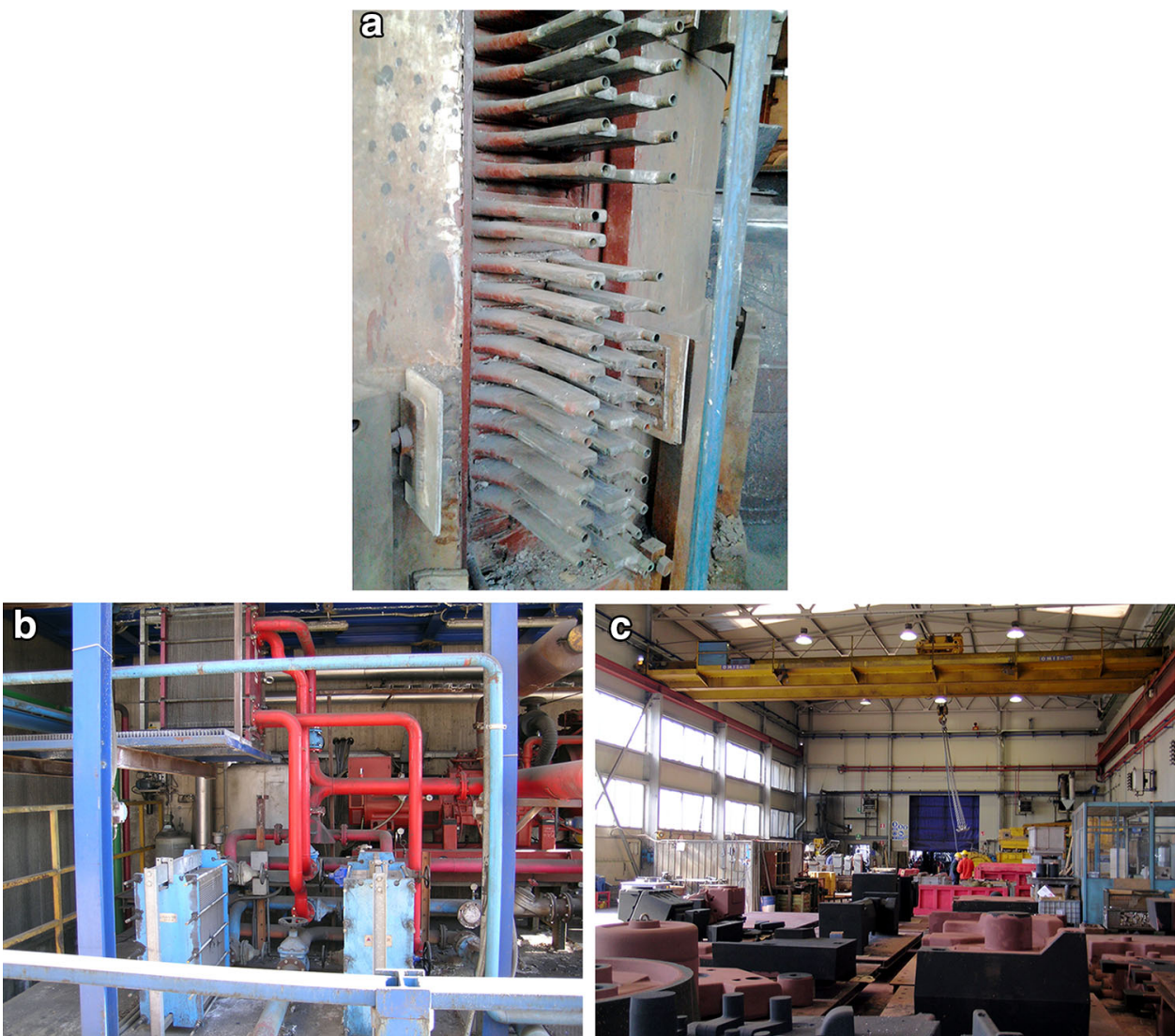
Table 6 Measured data during the audit concerning thermal energy recovered and electrical energy consumed by furnaces

\begin{tabular}{ll}
\hline Cooling tower water circuit & \\
Water flow rate $\left(1 \mathrm{~s}^{-1}\right)$ & 58.0 \\
$T_{\text {in }}$ cooling tower $\left({ }^{\circ} \mathrm{C}\right)$ & 35.6 \\
$T_{\text {out }}$ cooling tower $\left({ }^{\circ} \mathrm{C}\right)$ & 28.3 \\
Thermal power $(\mathrm{kW})$ & 1,773 \\
Furnaces circuit & \\
Cooling water flow rate $\left(1 \mathrm{~s}^{-1}\right)$ & 75.0 \\
$T_{\text {in }}$ furnaces $\left({ }^{\circ} \mathrm{C}\right)$ & 34.3 \\
$T_{\text {out }}$ furnaces $\left({ }^{\circ} \mathrm{C}\right)$ & 40.0 \\
Thermal power $(\mathrm{kW})$ & 1,790 \\
Active power (kW) & \\
Furnace 1 (CIME 2011) & 2,300 \\
Furnace 2 (Junker 1992) & 370 \\
Furnace 3 (Junker 1992) & 278 \\
Furnace 4 (CIME 2005) & 3,700 \\
Furnace 5 (CIME 2007) & 140 \\
Total furnaces & 6,788 \\
Thermal energy recovered by total melting power & $26.2 \%$ \\
\hline
\end{tabular}

consumption and saves the data, building up a characteristic curve on which the process controller synchronises all the furnaces' separate cycle times to create a balanced load profile with no peaks in consumption. This can limit the demand charge due across the year as a whole. Furthermore, such intelligent control systems can increase energy saving as well with respect to traditional "in series" disconnection furnaces management; in fact they do not disconnect furnaces in series (for the first furnace in the series to be disconnected, the melting times would rise noticeably) but merely reduce their demand simultaneously for a brief time. The reduction is hardly noticeable and leads to an almost imperceptible lengthening of the melting process [16].

A final observation must be devoted to heat losses due to radiation and convection from a furnace. The use of low density, low thermal conductivity and low thermal mass ceramic fibre materials as a hot face lining can minimise the loss of heat to the furnace structure. To face the disadvantage of low mechanical strength, they are sometimes used in sandwich fashion with other refractory materials, such as high-density brick or castables, insulation brick or low-temperature boards [17].

\section{Ladles}

In the maintenance and relining of ladles, the traditionally used refractory materials required labour intensive work and long drying times. In addition, the rather poor

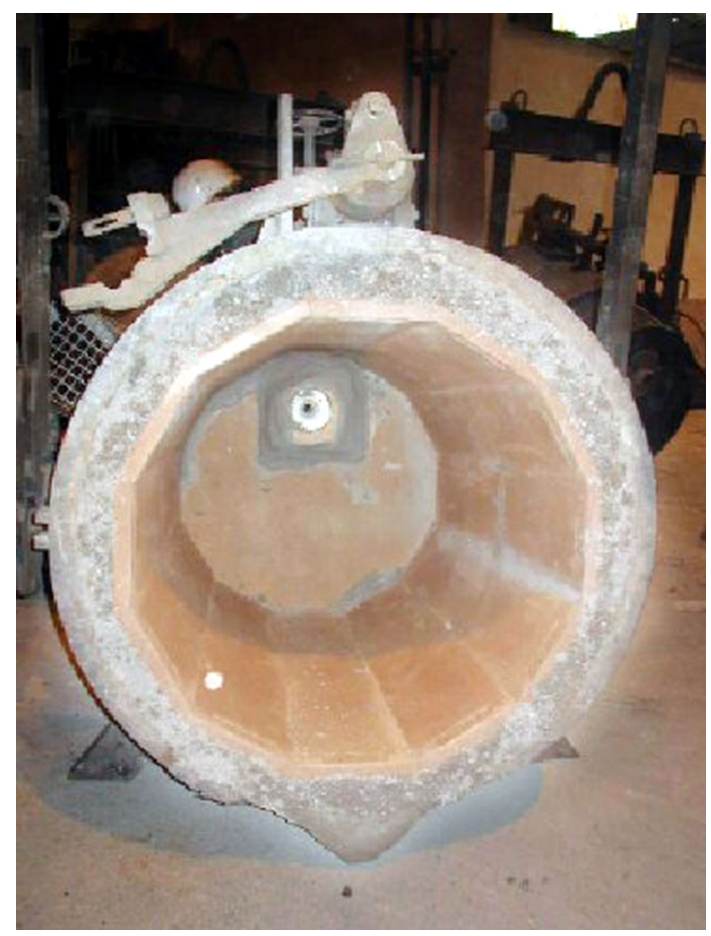

Fig. 10 Example of new lining materials with low density and low conductivity for ladles (courtesy of Foseco)

insulating capacity of the material required constant and intensive heating when not in use. New lining materials with low density, low thermal conductivity and non-wetting characteristics are nowadays available (Fig. 10). The benefits are labour and time savings, and substantial energy savings. Consider that during the audit in one of the foundries the external surface temperature of a ladle was measured as to be $240{ }^{\circ} \mathrm{C}$. Considering a ladle of $1 \mathrm{~m}$ diameter and $1.2 \mathrm{~m}$ height, the convection coefficient between ladle and air can be estimated as to be $10 \mathrm{~W} \mathrm{~m}^{-2} \mathrm{~K}^{-1}$, the emissivity of external surface to be 0.79 , so it is easy to estimate a thermal power loss around $20 \mathrm{~kW}$ (considering negligible radiation thermal losses by the melt cast iron because supposing the ladle covered).

As opposed to the former requirement of keeping the preheating burners for the ladles on for $24 \mathrm{~h}$ a day to maintain the ladle temperature, the new lining allows preheating of the ladle for only $2.5 \mathrm{~h}$ at the beginning of the work week. After that, the excellent insulating characteristics of the material obviate the need for preheating. As well, the molten metal tapping temperature could be lowered, because the transit temperature losses were substantially reduced (e.g. from an average of $50{ }^{\circ} \mathrm{C}$ down to $15^{\circ} \mathrm{C}$ ). Linings can typically last $12-18$ months. For one of the audited foundries, the consumption of the three natural gas burners (two of $300 \mathrm{~kW}$, one of $450 \mathrm{~kW}$ ) to heat the ladles was estimated to be 3,700 MWh (with a 
total thermal energy consumption of 5,900 MWh over one year). If the foundry adopts such lining materials saving even $30 \%$ of the ladles heating energy, it would save annually.

$$
0.37 \frac{€}{\mathrm{Sm}^{3}} \cdot\left(\frac{3700000 \mathrm{kWh}}{9.6 \mathrm{kWhSm}^{-3}}\right) \cdot 30 \%=42800 €
$$

\section{Mould making}

Mould making may consume as much as $20 \%$ of all energy in the foundry, depending on the technology used. The prevalent green sand mould making consists of sand and clay receiving, conveying, preparation, delivery to the mould area, mould handling, shakeout, reclamation, reconditioning and more conveying [12]. In effect, in one of the foundries audited, yearly energy consumed (electrical + thermal) in the four different mould making plants was 9,200 MWh on the total of 45,300 MWh (comprehensive of core making and sand mould in Table 2)

To protect sand moulds and cores from high molten metal temperatures, foundries use refractory coatings. The coating is in the form of liquid wash. Typically waterbased washes are used, requiring a long drying period in gas or electric-resistance heated ovens. Application of infrared heating for mould coating could reduce the drying time by as much as $85 \%$ [12]. The energy saving stems from the controllability of the infrared unit, which brings the mould surface to the desired temperature and then cycles off in a predetermined time sequence. Less heat is dissipated into the surroundings.

\section{Plant services}

For sake of brevity, either energy savings in buildings heating and cooling will not be dealt with or in the electrical distribution system. (optimizing transformer size, increasing power factor, increasing efficiency of electrical motors). Two services will be analyzed: compressed air system and lighting.

\section{Compressed air system}

Compressed air is used for pneumatic equipment and machine tools. It is well known that only 10-20\% of input energy to the compressor reaches the point of end-use [13, 18]. Energy saving can be reached by different strategies, ordered by decreasing cheapness:

- the correct location of air compressors and the quality of air drawn. Consider that the hotter the air drawn, the higher the power requested to compress it (in the order of $0.3 \%$ per degree Celsius); the wetter the air drawn, the higher the power requested to desiccate it. For example, in one of the foundries audited, the compressors were installed in an underground big room;

- the correct choice of outlet pressure, that is usually set equal to the requirement of the equipment which demands the highest pressure (increase in air discharge pressure by 1 bar above the desired value will result in an increase in the requirement of input power by about 6-10\%). For this reason, it can be useful to put together users of compressed air on the basis of the pressure they require and then set up two or more compressed air grids if needed;

- the minimisation of the pressure drop in the distribution line due, for example, to inadequate pipe size or choked filter elements, and the minimisation of air leaks conducting leakage test regularly. In two of the audited foundries a 1 week continuous measurement of air flows, pressures and current consumed by compressors was done in order to build a load curve for a typical week;

- when several compressors are present, the pressure setting of them should be adjusted so that only the one with the smallest size handles the load variation (modulation varying the flow rate); the others should operate with full load, to the extent possible. The full/ null load control is the most common strategy (the compressor is off when the maximum value of pressure set is reached, it turns on when the pressure decreases below the minimum set point). In the last years speed modulating compressors controlled by inverters are more and more widespread: in this case the rotating velocity of compressor is reduced when maximum pressure is reached in order to avoid the number of on/ off and so the starting current absorption;

- the heat recovery. In screw compressors (actually the most widespread), the heat of the polytropic process can be recovered by cooling the lubricant and the coolant [19].

Table 7 Lighting levels (in lux) throughout foundries [12]

\begin{tabular}{|c|c|c|c|c|c|c|}
\hline \multirow[t]{2}{*}{ Area } & \multicolumn{3}{|c|}{ Typical level range } & \multicolumn{3}{|c|}{ Required for workers aged } \\
\hline & Min & Max & Avg & Under 40 & $40-55$ & over 55 \\
\hline Moulding & 32 & 3,229 & 441 & 1,076 & 1,615 & 2,153 \\
\hline Pouring & 65 & 4,844 & 678 & 538 & 807 & 1,076 \\
\hline Core making & 54 & 3,229 & 527 & 807 & 1,076 & 1,615 \\
\hline Grinding & 43 & 1,938 & 603 & 1,076 & 1,615 & 2,153 \\
\hline Inspection & 22 & 1,259 & 527 & 1,076 & 1,615 & 2,153 \\
\hline
\end{tabular}


Table 8 Light bulbs comparison [20]

\begin{tabular}{|c|c|c|c|c|}
\hline Lighting type & Efficacy $\left(\operatorname{lm~} \mathrm{W}^{-1}\right)$ & Life-time (h) & Colour rendering index & Color temperature $(\mathrm{K})$ \\
\hline \multicolumn{5}{|l|}{ Incandescent } \\
\hline Standard "A" bulb & $10-17$ & $750-2,500$ & 98-100 (excellent) & $2,700-2,800$ (warm) \\
\hline Halogen & $12-22$ & $1,000-4,000$ & 98-100 (excellent) & $2,900-3,200$ (warm to neutral) \\
\hline \multicolumn{5}{|l|}{ Gas discharge-fluorescent } \\
\hline Straight tube & $30-110$ & $7,000-24,000$ & 50-90 (fair to good) & $2,700-6,500$ (warm to cold) \\
\hline Compact fluorescent lamp & $50-70$ & 10,000 & $65-88$ (good) & $2,700-6,500$ (warm to cold) \\
\hline Circline & $40-50$ & 12,000 & & \\
\hline \multicolumn{5}{|l|}{ Gas discharge-HID } \\
\hline Mercury vapour & $25-60$ & $16,000-24,000$ & 50 (poor to fair) & $3,200-7,000$ (warm to cold) \\
\hline Metal halide & $70-115$ & $5,000-20,000$ & 70 (fair) & $3,700($ cold $)$ \\
\hline High-pressure sodium & $50-140$ & $16,000-24,000$ & 25 (poor) & 2,100 (warm) \\
\hline Low-pressure sodium & $60-150$ & $12,000-24,000$ & $<44$ (very poor) & \\
\hline \multicolumn{5}{|l|}{ Solid-state lighting-LEDs } \\
\hline Cool white LEDs & $60-92$ & $25,000-50,000$ & 70-90 (fair to good) & $5,000($ cold $)$ \\
\hline Warm white LEDs & $27-54$ & $25,000-50,000$ & $70-90$ (fair to good) & 3,300 (neutral) \\
\hline
\end{tabular}

\section{Lighting}

Any action aimed at increasing lighting energy efficiency should not diminish the requirements of adequate lighting of the workplaces (Table 7). In one of the audited foundries, the substitution of $400 \mathrm{~W}$ metal halide lamps with 300 W LED lamps implied an increased illuminance: from 80 to $250 \mathrm{~lx}$ on the plan $0.8 \mathrm{~m}$ height from the ground.

Two main strategies are possible, adoptable in series.

\section{Light bulbs replacement}

To make a quick assessment of energy savings deriving from replacing light bulbs, data such as the ones collected in Table 8 come very handy together with an updated profile of the different light bulbs prices and data about the operating hours of the luminaires themselves. In retrofitting applications, a careful economic analysis has to be done to evaluate the advantage of the most innovative substitution of high intensity discharge (HID) lamps with the new light emitting diode (LED) because of the higher cost of a suitable new lighting fixture.

The most common light bulbs replacement interventions are: replacement of standard incandescent lamps with compact fluorescent lamps or LEDs (up to 75-80 \% savings, with about $15 € /$ bulb yearly total savings); replacement of inefficient fluorescent tubes (T12) with more efficient ones or LEDs (40\% energy savings with about $30 € /$ fixture yearly savings); replacement of mercury vapour light bulbs and high-pressure sodium with lowpressure sodium or LEDs: low-pressure sodium lamps can save about $40 \%$ versus high-pressure ones and more than
Table 9 Energy and economic results of the retrofitting of the lighting plant of one of the audited foundries

\begin{tabular}{lll}
\hline $\begin{array}{l}\text { Purchase and installation LEDs } \\
\text { Decommissioning of the present light. plant }\end{array}$ & $€$ & 376,377 \\
Global service for 7 years & & \\
Yearly rate for rental & $€$ year $^{-1}$ & 4,174 \\
Yearly saving for maintenance & $\mathrm{kWh} \mathrm{year}^{-1}$ & 373,531 \\
Energy saving & $€ \mathrm{kWh}^{-1}$ & $0.17-$ \\
Electrical energy cost & & 021 \\
& $€$ & 501,652 \\
Total energy saving (7 years) & $€$ & 34,925 \\
Energy efficiency bonds (7 years) & $€$ & 565,795 \\
Total saving (7 years) & year & 5 \\
Simple pay-back & & \\
\hline
\end{tabular}

$60 \%$ if compared to old mercury vapour fixtures. For the retrofits applications listed above, payback periods in literature can be as low as 0.5 years [20], but longer ones are at the moment associated with LEDs replacements due to high present cost of the technology itself. For example, for one of the foundries audited a detailed analysis of the substitution of the 757 lamps (metal halide and T8 fluorescent tubes) with LEDs has given the results reported in Table 9. In this case a "global service" proposal has been done: the foundry would pay a rental for seven years comprehensive of purchase and installation of LEDs plant, decommissioning of the present lighting plant, maintenance costs and energy efficiency bonds ("certificati bianchi"); a simple payback time of 5 years would be obtained. 


\section{Lighting control}

The two main solutions for lighting controls are

- dimming: generates energy savings by reducing the electric lighting level away from the recommended standard according to occupants' lighting preferences; it could be continuous from full power to off or low level, or discrete levels can be provided;

- occupancy sensing: lights are turned off when a zone is vacated; different sensors are available in the market, and recent developments have seen the usage of ultrasonic sensor constantly detecting presence without the risk of switching off lights due to occupants lack of movements.

Daylight harvesting can be usefully coupled to control lighting techniques dimming the light accordingly to daylight availability measured through the deployment of photosensors. The signal from the photosensors is interpreted by a lighting control module, an automated light switching device that can reduce the electric lighting by shutting off or dimming fixtures as appropriate. If electric lights are dimmable, then the artificial lighting may be continuously adjusted in proportion to the amount of daylight available. If the electric lighting is on-off only, then a fixture or lamp must remain on at full output until daylight can meet the entire recommended light level for the space. Dimming systems are generally more expensive than onoff systems, but have the potential to save more energy, because they can reduce electric light output when daylight can only partially meet the needs of the space.

\section{Conclusions}

Even a small reduction of the high energy demand of foundries can be appreciable as absolute value. In this industry, low level heat is of limited use so that heat recovery must operate either for air combustion preheating or for power generation with steam or organic Rankine cycles. Recuperative burners can be very effective in mould making furnaces. As far as electric induction furnaces are considered energy savings as high as $30 \%$ can be produced with an easy heat recovery to heat office building and other factory departments. Some benefits can be gained also by a better insulation both of the furnaces and of the ladles.

Plant services are other items for energy savings opportunities. Compressed air service and lighting offer good possibilities of energy savings with better management of these services and the improvement of the technology that regards both compressors and lighting systems.
Acknowledgments We wish to thank CPV (Centro Produttività Veneto) of Vicenza for the opportunity of co-operating with some foundries in the Vicenza province.

Open Access This article is distributed under the terms of the Creative Commons Attribution License which permits any use, distribution, and reproduction in any medium, provided the original author(s) and the source are credited.

\section{References}

1. ENEA: Rapporto Annuale Efficienza Energetica (Annual Report on Energy Efficiency). ISBN 978-88-8286-300-5. Dec. 2013. www.efficienzaenergetica.enea.it. Accessed 2 May 2014

2. ASSOFOND: La fonderia nel 2012 (Foundry in 2012). www. assofond.it (2013). Accessed 2 May 2014

3. ASSOFOND Energia: Seminario sui mercati energetici (Workshop on energy markets). www.assofond.it (2013). Accessed 2 May 2014

4. Ozawa, L., Martin, N., Worrell, E., Price, L.: Energy use and $\mathrm{CO}_{2}$ emissions in Mexico's iron and steel industry. Energy 27, 225-239 (2002)

5. Price, L., Sinton, J., Worrell, E., Phylipsen, D., Xiulian, H., Ji, L.: Energy use and carbon dioxide emissions from steel production in China. Energy 27, 429-446 (2002)

6. Worrell, E., Price, L., Martin, N.: Energy efficiency and carbon dioxide emissions reduction opportunities in the US iron and steel sector. Energy 26, 513-536 (2001)

7. Yih-Liang Chan, D., Yang, K.H., Lee, J.D., Hong, G.B.: The case study of furnace use and energy conservation in iron and steel industry. Energy 35, 1665-1670 (2010)

8. Thollander, P., Karlsson, M., Soderstrom, M., Creutz, D.: Reducing industrial energy costs through energy-efficiency measures in a liberalized European electricity market: case study of a Swedish iron foundry. Appl. Energy 81, 115-126 (2005)

9. Trianni, A., Cagno, E., Thollander, P., Backlund, S.: Barriers to industrial energy efficiency in foundries: a European comparison. J. Clean. Prod. 40, 161-176 (2013)

10. Thollander, P., Backlund, S., Trianni, A., Cagno, E.: Beyond barriers - a case study on driving forces for improved energy efficiency in the foundry industries in Finland, France, Germany, Italy, Poland, Spain, and Sweden. Appl. Energy 111, 636-643 (2013)

11. Thollander, P., Mardan, N., Karlsson, M.: Optimization as investment decision support in a Swedish medium-sized iron foundry - a move beyond traditional energy auditing. Appl. Energy 86, 433-440 (2009)

12. Canadian Foundry Association: Energy Efficiency Opportunities in Canadian Foundries. Catalogue No. M92-262/2003E. ISBN 0-662-33438-8 (2003)

13. Small Industries Development Bank of India: Energy conservation measures in the foundry sector. Winrock International India, Haryana. www.msmementor.in. Accessed 22 April 2014

14. Helber, J., Steinhäuser, M.: D19 Good practice guide on energy saving potentials and opportunities for foundries. Doc. ID: Foundrybench_D19_12122011 (2011)

15. European Commission: Reference Document on Best Available Techniques in the Smitheries and Foundries Industry. http:// eippcb.jrc.ec.europa.eu/reference (2005). Accessed 19 April 2014

16. Dr. Tanneberger GmbH: Padicon, Brochure. www.tanneberger. de. Accessed 3 May 2014

17. Foseco International Limited: Furnace lining systems, Brochure. www.foseco.com. Accessed 3 May 2014 
18. Anglani, N., Mura, P.: Opportunità di ottimizzazione dei consumi nella produzione, distribuzione, utilizzo dell'aria compressa nei settori industriali più sensibili (Optimisation of energy consumption in production, distribution, use of compressed air in most sensible industrial sectors). Report RdS 2010/222, ENEA. (2010)

19. Noro, M., Viero, L.: Possibilità di recupero energetico negli impianti di climatizzazione industriale (Energy saving opportunities in industrial air conditioning plants). Proc. Conf. AiCARR "Riduzione dei fabbisogni, recupero di efficienza e fonti rinnovabili per il risparmio energetico nel settore industriale" ("Energy needs reduction, efficiency recovery and renewables for energy saving in industry"), pp. 81-129. ISBN 978-88-95620-374. Padua (2010)

20. Moret, S.: Energy efficiency in lighting: daylight harvesting optimization and wireless sensor networks. Degree thesis, University of Padua. Padua (2012)

21. Wünning, J.G.: Flox ${ }^{\circledR}$ - flameless combustion. Thermoprocess Symposium (2003) 